\title{
Improving Students' Learning Outcomes In Practical Physics, Which Is Better? Computer Simulated Experiment or Hands-On Experiment?
}

\author{
Benson Adesina Adegoke PhD, Nkiruka Chukwunenye
}

\begin{abstract}
In this study, the authors examined the effect of computer simulated experiment on students' learning outcomes in Physics practical. The sample consisted of 359 senior secondary school two students $(16-18$ years), who were randomly selected from six secondary schools in Oweri and Orlu Educational Zones in Imo State, Nigeria. There were three treatment groups: Computer Simulated Experiment only, Computer Simulated Experiment + Hands-on Experiment, and Hands-on Experiment only. Students' level of mathematical reasoning ability was also introduced to serve as moderator variable.

Students' combined scores in manipulative skills in physics practical (MSPP) and Physics achievement test (PAT) were used as dependent variable. Results showed that students who were exposed to both computer simulated experiment and hands-on experiment performed best among the three groups while students in the Hands-on Experiment group performed worst in MSPP and PAT. This results show the superiority of computer simulated experiment over hands-on experiment. It was interesting to note students with moderate mathematics reasoning ability performed best in all the groups. This findings shows that computer simulated experiments can be usedto enhance the performance of an average mathematical ability student. Therefore efforts should be made to equip physics laboratory with computer software that can be used for computer simulated experiments in physics practical.
\end{abstract}

Key words: Computer simulated experiment, Hands-on experiment, Physics practical, Mathematics reasoning ability, Achievement in physics

\section{Introduction}

The role of functional physics education in technological advancements of nations cannot be overemphasised. Highlydeveloped physics education, no doubt, is needed to keep on producing future engineers, technologists and scientists for driving the economic engines of the nation. Any country who decides to pay lip service to the development of her physics education will surely lag behind others in the comity of nations. It is against this background that the major stakeholders (e.g. physics teachers, parents, public examining bodies and government officials) in physics education in Nigeria continue to express worries about the declining level of enrolment and performance of Nigerian students in physics, especially at secondary school level.

The statistics of enrolment of students for senior secondary school certificate examination (SSSCE) being conducted by West African Examination Council (WAEC) and National Examination Council (NECO) shows that on the average, in the last three years, less than $40 \%$ of the total candidates who registered for SSSCE in Nigeria actually registered for physics. On achievement, the level of achievement of candidates between 2010 and 2012 was below 50\%. In fact the percentage of candidates, who passed at the minimum credit level (C6), on the average, was below $45 \%$. A pertinent question that arises is what went wrong?

From the WAEC Chief Examiners' Report for 2010, 2011, and 2012 attention is being drawn to the fact that students are not doing well in practical physics. Some of the aspects of physics practical where students are exhibiting problems include: optics (use of protractor, parallax error arising from sighting of images, reading of values and measurement of angles from laboratory instruments) and simple Harmonic Motion (Measurement of time, taking of period of oscillation and extension of spiral spring and determination of acceleration due to gravity). Other related problems identified included: wrong responses to questions bordering on the theory of the experiment, inability to plot graphs involving small values and make deductions from the graphs. These findings as enumerated in the WAEC Chief Examiners' Report indicate that students do not have requisite skills in physics practical. This may therefore be one of the reasons why students continue to perform poorly in physics.

The importance of practical work in students' learning of physics can not be overemphasised. According to Azar and Şengülec (2011), practical activities in physics, improve students' learning, help develop positive attitude towards physics and more importantly engender permanence of knowledge. Earlier Tamir(1977) listed the aims of using laboratories in science education as follows: To help students (a) 
comprehend abstract and complex scientific concepts by using concrete materials, (b)develop problem solving and analytical skills, (c) develop practical skills and (d) develop positive attitudes towards science.

The National Policy on Education of the Federal Government of Nigeria (FGN, 2004) advocates the inquiry-based learning for all science instructions and classroom activities. "Learning by doing" science experiments is recommended as one of the effective ways to promote the learning of scientific concepts, and help secondary school students acquire process and problem skills. No doubt, experimental work in the sciences especially in Physics, Chemistry and Biology is very important and a basic requirement in secondary school learning of sciences. It is, however, unfortunate that laboratory sessions which ideally should follow at the end of every module is sparingly organised for secondary school students (WAEC Chief Examiners' Reports 2010, 2011, 2012). This iseither due to ill-equipped laboratories in most public schools or lack of interest or laziness on the part of the teachers (Ariyo, 2006; Kuti, 2012). For example, Kuti (2012) stressed that most secondary schools in Nigeria lack functional physics laboratory. Moreover, time apportioned to physics on the school time table (three periods of 40 minutes each per week) is not enough to accommodate laboratory sessions (Chukwuneye, 2011). Research (e.g., Chukwuneneye, 2012) shows that quite a number of physics teachers usually pay attention to completing the scheme of work rather than on the quality of teaching. Therefore, ample opportunity needed by the students to develop skills and appropriate approaches to scientific activities and exploration is not made possible.

No doubt, lack of functional physics laboratory and inadequate equipment for physics practical in most Nigerian secondary schools is hampering laboratory activities and these may be contributing to low level of performance of students in physics. To overcome these obstacles, it is possible through the use of computer programs to form simulations and animations of physics experiments. This according to Azar and Şengülec, (2011) can help to mitigate the negative effects of lack of laboratory on students' learning outcomes in physics.In recent years, as noted by Chukwunenye (2012) computer programs such as Interactive Physics, Physics Education Technology (Ph.ET) Interactive Simulation, Crocodile Physics, Edison 4.0 and Virtual Labs, have been developed to present physics experiments in a virtual laboratory with the aid of a computer. These computer-based simulations are computer generated versions of real world objects or processes which can be presented in two dimensional texts-driven formats or three dimensional multimedia formats.

In physics experiments, computer-based simulations can take various forms ranging from computer readings of three dimensional geometric shapes to highly interactive computerised laboratory experiments. These experiments, in fact, can be carried out in the classroom and even in our private rooms. Research (e.g.Azar and Şengülec, 2011; Şengel\&Özden, \&Geban, 2002; Kun-Yuan Yang \&Jia-Sheng, Heh 2007) has shown that computer simulated experiments have great potentials for improving students' learning outcomes in physics practical. Studies of Azar and Şengülec, (2011) and Adams, Finkelstein, Reid, Dubson, Podolefsky, Wieman, Lemaster, Mckagan, (2008) have laid credence on the improvement of students' learning outcomes in physics through the use of computer simulated experiments.

A current trend in Western Europe, Asia and USA is the use of computer simulated experiments (Chukwuneneye, 2012). In Nigeria and most developing countries in South of Sahara, the use of computer simulated experiments (CSE) in physics practical is virtually non-existent. Literature in physics education indicates that virtually no study has been carried out on CSE in Nigeria and indeed the whole West Africa. It is on the basis of this that this study was conceived. The study sought to determine the extent to which computer simulated experiments can improve students' learning outcomes in theory of practical and improve practical skills of Nigerian secondary school students.

In the school system, the use of hands-on-experiments in the real-life physics situations cannot be totally abandoned. They have their merits too. Hands-on experiments $(\mathrm{HoE})$ offer students concrete experiences and opportunities to confront misconceptions. No doubt, real life situations tend to make long lasting impressions than simulated situations. There is no replacement for students' hands-on experience as far as instrumentation and physical processes are concerned. No doubt, through hands-on experiments, students become active learners and acquire scientific skills and knowledge in a meaningful context. Past studies (e.g. Alkhalifah, 2005; Bayrak, Kanli, \&Kandilİngeć, 2007; Jimoyiannins\&Komis, 2000) show that CSE may not after all be better, as instructional method in physics practical, than hands-on experiment. For example,Alkahifah (2005) found out that there was no significant difference in the mean scores of students in the computer simulated experiments group and hands-on laboratory experiment group.

Theoretical physics as well as practical activities in the laboratory are surrounded by topics that involve the use of equations and formulae, measurements, reading of values, manipulative skills, perceptual and logicomathematical reasoning abilities. Therefore learning physics in the classroom as well as in the laboratory require mathematical reasoning ability. According to researchers (such as Adegoke, 2010; Kuti, 2012) familiarity with basic arithmetical operations are required to meaningfully learn physics concepts and by extension develop manipulative skills in practical activities. 
Mathematical Reasoning Ability (Adegoke, 2013), is a measure of students' familiarity with basic arithmetical operations, algebraic symbols and spatial figures. In Physics practical activities mathematical reasoning ability is needed to describe similarities and differences, create a correct mental picture of positions and figures and make functional deductions. For example in practical activities, students must be able to locate positions accurately and avoid parallax error, accurately read angles while using protractors, and measure lengths of objects using meter rule, vernier callipers, micrometer screw gauge and other measuring instruments. The extent to which mathematical reasoning ability correlates with practical activities in Computer Simulated Experiments are yet to be well documented in literature. Therefore, the second goal of this study was to determine the extent to which mathematical reasoning ability interacts with the CSE and hands-on experiment to influence students' achievement and manipulative skills in physics practical.

Constructivism as defined by Piaget (1983) serves as theoretical frame work for this study. According to the theory of constructivism, each child creates, or builds, or constructs meaning from experiences. In physics practical activities the child is the active agent, processing information and experience from the world. Using his or her mind like an erector set the child builds an increasingly complex set of cognitive structures to figure out what is going on in the real world. According to this theory, it is the discrepancy between the previous knowledge and the recent activities that create "cognitive conflict "which positions the learner for reflection and resolution through interactions with the learning environment.

The constructivist approach is based on the following principles:

1) Learning is an active process. Learners, based on their own prior knowledge or and experience, extend the system of knowledge through personal work or interaction with other sources in the learning environment. Learners are given more responsibility and ownership for learning to structure knowledge and solve problems actively according to their own interest, needs and learning purpose.

2) Sets learners in a learning community for developing, testing and modifying their ideas and sharing the intelligence of others by means of dialogue, debate, discussions and negotiation.

3) To gain practical knowledge and skills for other situations, learners have to be furnished with tools and resources to solve authentic problems

4) It is also essential to provide learners with learning scaffolding to excite the zone of proximal development.

The theory is relevant because during practical classes the learner brings the theoretical aspect including classroom demonstrations to bear in order to accommodate and generate further knowledge by interacting with the learning environment which in this study may be computer simulated environmentand real life laboratory situations.In fact one of the conditions for the use of CSE and of course hands-on laboratory practical is that the learner must have been exposed to the theoretical knowledge; it is on the basis of that knowledge and other recent activities that new knowledge will be constructed. Therefore it is in line with constructivism which emphasizes the importance of previous knowledge in a new learning situation.

The major task in this study centers on finding out in which of the learning environments will help students gain more knowledge, build more confidence and develop their manipulative skills. Is it with computer simulated experiments (CSE) or hands-on experiment (HoE) or in the combination of the two (CSE + HoE)? In addition the study focuses on finding out which categories of students will benefit maximally from each of the contrasting learning environments? Is it students with high mathematical reasoning ability? Is it moderate mathematical reasoning ability? or Is it low mathematical reasoning ability?

\section{Specifically, three hypotheses were tested. These were}

Hypothesis One: The mean scores of the students, in physics practical, in all the three treatment groups (CSE, CSE + HoE, and HoE) will be equal.

Hypothesis Two: The mean scores of the students, in physics practical, of each of the three levels of mathematical reasoning ability (High, Moderate and Low) will be equal.

Hypothesis Three: Interaction of treatments conditions (CSE, CSE + HoE, and HoE) and levels of mathematical reasoning ability (High, Moderate and Low) will not affect students' mean scores in physics practical.

\section{Participants}

\section{Methodology}

The participants were 359 Senior Secondary Two (Age 16 - 18 years) students randomly drawn from six Senior Secondary Schools in Oweri and Orlu Educational Zones 1, Imo State, Nigeria. In this study, only students in science classes took part. From each school, intact science classes were used. Among the 359 students sampled, $215(59.9 \%)$ were boys, while $144(40.1 \%)$ were girls. Their ages ranged between 16 and 18 years $($ Mean age $=15.97 ; \mathrm{SD}=1.79$ ).

\section{Materials}

Three instruments were used for data collection. These were: 
1. Manipulative Skills in Practical Physics (MSPP)

2. Physics Achievement Test (PAT)

3. Mathematical Reasoning Ability Test (MRAT)

MSPP: Students' manipulative skills were assessed from the graphs that students plotted after the end of each experiment. The construction of table of values and answers given to the problems at the end of each experiment were also assessed. Inter-scorer reliability was used to determine the reliability of the test. This was achieved by using two physics teachers to mark each of the students answer booklets. The reliability of scores was $0.86,0.71$ and 0.73 for CSE, HoE and CSE + HoE respectively.

PAT: It consists of 30 items drawn from simple pendulum and verification of Hooke's law. The items were placed on four options A, B, C and D. The tests were developed by the second author of this paper. The 30 items were drawn from the initial pool of 45 items. Fifteen items whose difficulty indices were either lower than 0.30 or greater than 0.80 were deleted. The difficulty indices of the remaining 30 items ranged from 0.63 and 0.74 . This was determined by using Kuder-Richardson 20 formula. The disseminating power of the items ranged from 0.37 to 0.51 .

MRAT: The author of this article constructed this instrument. It was constructed by combining the fundamental processes of recognition of variable, class, order and correspondence with the three basic types of materials employed in the study of Mathematics, these being arithmetical numbers, algebraic symbols, and spatial figures. As suggested by Lee (1967), separate tests were designed to estimate capacity for handling each of the four processes in terms of each of the three types of materials making twelve sub tests in all. Initially under each sub test, there were four items, that is, the draft copy consisted of 48 items. These items were subjected to pilot testing among 35 students in Ayedaade Local Government Area, Osun State, Nigeria. In each of the sub tests, items with low difficulty levels $(\mathrm{p}<.30)$ were eliminated. In the final draft, there were 24 in all. The difficulty and discriminating indices of each item ranged between 0.37 and 0.79 ; and 0.40 and 0.57 respectively. The reliability index of MRAT was between 0.79 .

\section{Examples of item used in the MRAT include:}

1. In each of the rows of numbers, there are five numbers on the left. Four have something in common and one is different. Underline the one which is different. When you have done this, place a circle on one of the numbers on the right which could best take the place of the one you have underlined.

Left

$45,54,63,27, \underline{\mathbf{3 0}}$

In this problem, on the left hand side, 30 have been underlined, because it is not divisible by 9 . On the right hand side, 36 have been circled because it is only one ofthe four numbers which is divisible by 9

2.The following rows show the beginnings of series of numbers, and some numbers are missing. Fill in the blank spaces with the numbers you think should be there.

$1,3,5,7,9,---,---$

Scores obtained by the students in MRAT were used to place them into three ability groups:

High $=67$ thpercentile and above

Medium $=34$ th percentile to 66 th percentile

Low $=$ Bottom 33th percentile.

\section{Software Package on Computer Simulated Experiments}

This CSE package is physics laboratory software adapted from online computer simulation laboratory or virtual physics laboratory. This laboratory is made up of hundreds of simulations ready for use in classroom activities. However for this study, interactive simulations on simple pendulum developed by Walter Fendt in 1998 and verification of Hooke's law developed by Ph.ET group in 2006 were chosen. The CSE package has been tested, updated and validated by various groups. Prominent among these various validation team is the Physics Education Technology Group Ph.ET (e.g. Adams, Finkelstein, Reid, Dubson, Podolefsky, Wieman, \&Lemaster, 2004;Adams, Finkelstein, Reid, Dubson, Podolefsky, Wieman, \&Lemaster, Mckagan, 2008).

\section{Hands on Laboratory Package}

These consist of physics materials usually found in a typical functional physics laboratory. They are retort stand, with clamp, bob, strings, scale pan, different masses and stopwatch.

\section{Procedure}

There were three groups: Group I $=\mathrm{CSE}$; Group II $=\mathrm{CSE}+\mathrm{HoE}$, and Group III $=\mathrm{HoE}$.

Group I (CSE, Number of participants $=128)$

Material used was CSE software through internet services. 
Step I: The process of logging on the Internet virtual laboratory was explained and the students after five practices mastered it.

Step II: Students were grouped. Four students were assigned to a computer. However, it was emphasised that each student should take his or her own readings.

Step III: The research assistants demonstrated how to use the virtual laboratory to conduct physics experiments.

Step IV: The assistant demonstrated how to take readings. The students practiced this procedure on the first meeting.

Students demonstrated competency after about six practices and the first session ended after about 35 minutes.

Second Session (Time 40 minutes)

Step VII: Individual students embarked on the given task and obtained readings from the simulated experiments.

Step VIII: Individual student used the data to plot graph and carry out calculations.

Group II (CSE + HoE Number of participants $=105)$

In this group, in addition to doing all the activities in Group I, they were also exposed to hands-on experiment of Group III

Group III:HoE (Number of participants $=126$ )

Materials used: Physics equipment for hands-on experiment in a typical functional laboratory.

Step I:The research assistant set up the apparatus for the experiment. The students observed the research assistant as he set up the apparatus for the experiment.

Step II: The students were grouped. Four students were assigned to a group. Each group was given a set of apparatus.

Step III: The students set up the apparatus and take readings. Later each student took his or her own readings.The research assistants moved round to monitor the activities. However, the assistants did not actively interfered in what the students were doing.

Step IV: Each student used the data to plot graph and carry out calculations.

In each group four different experiments were carried out in the three weeks scheduled for the experiment. All practical activities were carried out during the normal time scheduled for physics on the school's official time table. The six research assistants used in this study were undergraduates in their final year. These students are reading physics/education in one of the first generation universities in south-West, Nigeria.

Two assistants were assigned to each of the three groups. The two assistants in CSE and CSE + HoEare quite familiar with how to surf Internet and they have been trained on the use of virtual laboratory. The two assistants in HoE are familiar with and have carried out several experiments on Hooke's law and simple pendulum in their secondary school days as well as in the Department of Physics.

During the weeks of experiment, the author moved round to monitor laboratory activities in each school. The topics chosen are some of the topics scheduled for weeks 4,5 and 6 of first term in senior secondary school Two.

The first lesson was used to explain key concepts. For example, for pendulum, experiment, concepts such as oscillation, vibration, frequency and period were explained. The second lesson was devoted to experimental work.

Before the experiment, students' scores in the first term physics examination were obtained. Scores in physics in each school were standardised using z-score. These scores were used as pre-test. Also before the experiment, MRAT was administered to the students and their scores were used to classify them into High, moderate and low mathematical reasoning ability test. Immediately after the experiments, PAT was administered. The students used 35 minutes to complete the PAT. In this study, scores from MSPP and PAT were combined and used as the dependent variable, while treatment and MRA were the independent variables. The maximum score obtainable in MSPP was 30 and the maximum obtainable score in PAT was 30. These gave a total of 60 marks.

\section{Results}

A $3 \times 3$ pre-test, post-test, control group in a quasi-experimental design was adopted where the treatments (use of CSE,CSE + HoE and HoE) and Mathematical reasoning Ability (high, moderate, and low) were the independent variables.

Tables 1 present the descriptive statistics (mean and standard deviation of the students combined score in MSPP and PAT respectively).Table 2 presents the ANCOVA tests of between-group effects.

Table 1:Mean and Standard Deviation

\begin{tabular}{|c|c|c|c|}
\hline Group & Mean & SD & $\begin{array}{l}95 \% \text { Confidence Interval } \\
\text { Lower Bound Upper Bound }\end{array}$ \\
\hline TRT & & & \\
\hline $\mathrm{CSE}$ & 39.11 & 6.87 & 40.47 \\
\hline $\mathrm{CSE}+\mathrm{HoE}$ & 40.83 & 6.84 & 42.63 \\
\hline
\end{tabular}




$\begin{array}{lcccc}\text { HoE } & 35.69 & 7.51 & 34.12 & 37.26 \\ \text { MRA } & & & & \\ \text { High } & 44.00 & 7.36 & 40.76 & 47.24 \\ \text { Moderate } & 37.49 & 7.83 & 34.58 & 40.40 \\ \text { Low } & 33.62 & 7.55 & 31.86 & 35.39\end{array}$

Key: TRT - Trent, ESE = Computer Simutated Experiment, HoE = Hands-on Experiment, CSE + HoE $=$ Combined Computer Simulated Experiment and Hands-on Experiment, MRA = Mathematical reasoning Ability

\section{Testing of Hypotheses}

Hypothesis One: The mean scores of the students, in physics practical, in all the three treatment groups (CSE, CSE + HoE, and HoE) will be equal.

Table 1 show that students in the combined CSE + HoE had the highest mean score $(\mathrm{M}=40.83 ; \mathrm{SD}=6.84)$ in physics practical scores, followed closely by the students in CSE Group while those in the HoE had the lowest mean score. The mean difference in scores among the three treatment groups was statistically significant $\mathrm{F}$ ( 2 , $351)=15.59, \mathrm{p}<.001, \eta^{2}=0.082$ (see table 2 ). The effect size of $8.2 \%$ was moderate.

Sidak adjustments for multiple comparison show that the mean scores of students in CSE and CSE + HoE were significantly better $(\mathrm{p}<.05)$ than the mean score of students in HoE group. There was no significant difference in the mean score of students in CSE and CSE + HoE.

Table 2: Tests of Between-Subjects Effects

\begin{tabular}{|c|c|c|c|c|c|c|}
\hline Source & $\begin{array}{r}\text { Type III Sum of } \\
\text { Squares }\end{array}$ & $\overline{\mathrm{Df}}$ & Mean Square & $\mathrm{F}$ & Sig. & Eta Squared \\
\hline Corrected Model & 3475.055 & 7 & 496.436 & 10.438 & .000 & .172 \\
\hline Intercept & 12652.590 & 1 & 12652.590 & 266.036 & .000 & .431 \\
\hline Covariates & 892.248 & 1 & 892.248 & 18.761 & .000 & .051 \\
\hline TRT & 1483.173 & 2 & 741.587 & 15.593 & .000 & .082 \\
\hline MRA & 1058.220 & 2 & 529.110 & 11.125 & .000 & .060 \\
\hline TRT *MRA & 398.560 & 2 & 199.280 & 4.190 & .016 & .023 \\
\hline Error & 16693.430 & 351 & 47.560 & & & \\
\hline Total & 505958.000 & 359 & & & & \\
\hline
\end{tabular}

Hypothesis Two: The mean scores of the students, in physics practical, of each of the three categories of mathematical reasoning ability (High, Moderate and Low) will be equal.

Table 1 show that students who were classified as being high in MRA had the highest mean score $(\mathrm{M}=44.00$; $\mathrm{SD}=7.36$ ) in physics practical followed by the students in moderate group while those in the low group had the lowest mean score. The mean difference in scores among the three MRA groups was statistically significant $F$ $(2,351)=11.13, p<.001, \eta^{2}=0.060$ (see table 2$)$. The effect size of $6.0 \%$ was moderate.

Sidak adjustments for multiple comparison show that the mean scores of students who were classified as being high in MRA was significantly best among the three groups $(p<.05)$. There was no significant difference, in the mean scores, between moderate group and low group.

Hypothesis Three: Interaction of treatments conditions (CSE, CSE + HoE, and HoE) and levels of mathematical reasoning ability (High, Moderate and Low) will not affect students' mean scores in physics practical tests.

Table 3 show the mean score of the MRA classification of students in each of the treatment groups.

Table 3: Treatment * Mathematics Reasoning Ability

\begin{tabular}{|c|c|c|c|c|}
\hline TRT & MRA & $N$ & Hent & $\rightarrow$ SD \\
\hline \multirow{6}{*}{$\mathrm{CSE}+\mathrm{HoE}$} & High & 46 & 39.00 & 6.45 \\
\hline & Moderate & 23 & 36.00 & 7.83 \\
\hline & Low & 59 & 39.48 & 6.64 \\
\hline & High & 30 & 38.43 & 6.98 \\
\hline & Moderate & - & - & - \\
\hline & Low & 75 & 38.61 & 6.84 \\
\hline \multirow[t]{3}{*}{$\mathrm{HoE}$} & High & 37 & 34.92 & 8.18 \\
\hline & Moderate & - & - & - \\
\hline & Low & 89 & 32.74 & 7.17 \\
\hline
\end{tabular}

Table 3 shows among the students in CSE (which is the group with highest mean score), students who were classified as being low in MRA had the highest mean score in physics practical followed by the students in high group while those in the moderate group had the lowest mean score. From the table, generally all categories of MRA in the HoE group had the lowest mean score among the three groups. The mean difference in scores as a result of the interaction was statistically significant $\mathrm{F}(2,351)=4.19, \mathrm{p}=.016, \eta^{2}=0.023$ (See table 2). The effect size of $2.3 \%$ was fair. 
To disentangle the interaction a plot of the mean scores in Table 3 was carried out. The graph is shown in Figure 1 .

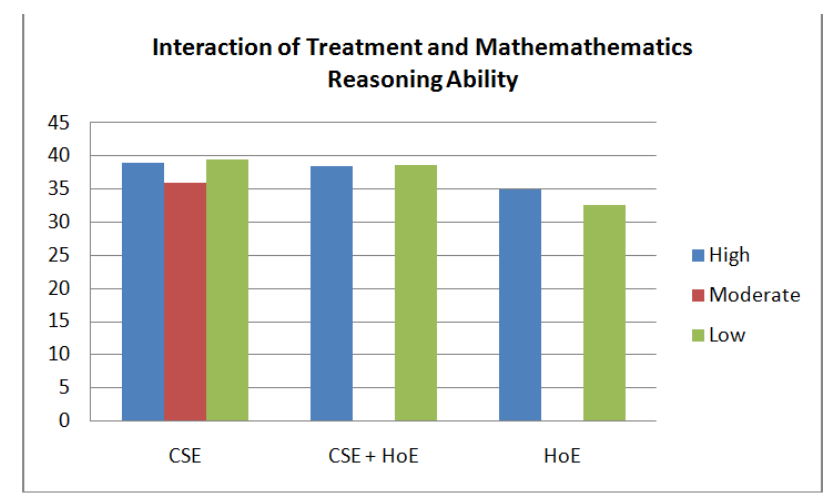

Figure 1: Interaction of TRT and MRA

\section{Discussions, Conclusion and Recommendation}

The main goal of this study was to find out in which learning environment do students tend to gain practical skills and achieve best in physics. The study showed that students who were exposed to computer simulated experiments only and those exposed to both computer simulated plus hands-on experiment performed far better than students who were exposed to the combination of hands-on experiment only. In addition, it is interesting to note that the difference in the mean score between those in CSE + HoE and those in CSE only was very small and not statistically significant. This is in agreement with Azar and Şengülec (2011) and Zacharia and Anderson (2003). Their findings showedthat student who learnt physics practical through CSE gain conceptual understanding more compared to the learners taught by the conventional laboratory method. However, the findings are not in consonance withthat of Bayrak, Kanli, Kandil (2007) and Alkhalifa (2005) who found no significant difference in mean scores of students in computed simulated experiments and those who were in the normal hands-on experiments.

These findings imply that students' performance in physics could be optimally improved through the use of CSE. This is in agreement with Azar, andSSengülec, (2011)These findings show that CSE has great potentials for improving learning outcome in physics practical. The use of combination of CSE andHoE is equally of essence in our attempt to improve the learning outcome of physics. There exist a wide range of mean gain in score between CSE $+\mathrm{HoE}$ and $\mathrm{HoE}$ only group. This shows that when students learn physics practical through simulation and hands-on there will be an improvement in their learning outcomes. This is in agreement with Zachariaand Anderson (2003) and Yu Fen-Lee, Yu Ying Guo, and Hsiang-Ju(2008) and Kun-Yuan Yang and Jia-Sheng, Heh (2007)who said that the use of combined CSE and HoE could help students make acceptable predictions and explanations of the phenomena in focus better than hands-on laboratory activities alone.

It is quite interesting to note that all categories of students not withstanding their mathematical reasoning ability tend to gain maximally from CSE and in the combination of CSE and HoE. The use of computer simulated experiments removed the effect of mathematical reasoning ability. These findings show that the perceived abstract nature of physics may be removed if computer simulated experiments are used in schools. This is agreement with Adegoke (2011) and Kuti, (2012) that the use of multimedia may reduce the abstract nature of physics and consequently be used to attract more students to physics.

\section{References}

[1] Adams, W.K. Finkelstein, N.D. Reid, S. Dubson, N., Podolefsky, N. Wieman, C.E. and Lemaster, R.Mckagan, S.B. (2008). A Study of Educational Simulations Part I: Engagement Learning. Journal of Interactive Learning Research. 19, 397-419.

[2] Adegoke, B.A. (2011). Effect of Multimedia instruction on senior secondary school students' achievement in Physics.Journal of Educational Studies, 3, 537 - 550

[3] Alkhalifah, A.A. 2005. Investigating Students' Learning with Web-based Virtual Laboratory Activities Using Computer Simulations.College of telecommunication Department, Riyadh Saudi Arabia.Retrieved June 20,2012 from http://elexforum.hbmeu.ac.ae/proceeding/pdf/inv.

[4] Ariyo, A. O. (2006). School and student factors as determinants of students' achievement at the secondary school level in Oyo State, Nigeria.Unpublished Doctoral Thesis, University of Ibadan, Nigeria

[5] Azar, A., Şengülec, Ö.A. (2011). Computer-Assisted and Laboratory Assisted teaching methods in physics teaching: The effect on student achievement and attitude towards physics. Eurasian Journal of Physics and Chemistry Education (Special Issue) 43 - 50.

[6] Bayrak, B., Kanli, U., Kandilİngec (2007) To compare the effects of computer based learning and the laboratory based learnimg on students' achievement regarding electric circuits. The Turkish Journal of Educational Technology, 6, 15 - 24

[7] Chukwunenye, J. N. (2011). Effects of two modes of computer simulated experiment on senior secondary school students' achievement and interest in practical physics. Pre field seminar Paper, Department of Teacher Education, University of Ibadan, Nigeria.

[8] Federal Government of Nigeria (2004).National Policy on Education, Lagos: NERDC. 
[9] Jimoyiannis, A., \&Komis, V. (2000). Computer simulations in physics teaching and learning: A case study on students' understanding of trajectory motion. Computers \& Education, 36, 183 - 204

[10] Kun-Yuan Yang and Jia-Sheng, Heh (2007). The impact of internet virtual physics laboratory instruction on achievement in physics, science process skills and computer attitude of $10^{\text {th }}$ Grade Students. American Journal of Science Education and Technology. 16, $451-461$.

[11] Kuti, J.B. (2012). Effect of split attention multimedia principle and cognitive load on senior secondary school students' retention in Quantum Physics in Ogun State, Nigeria. Unpublished Ph.D. thesis, University of Ibadan, Nigeria.

[12] Lee, D. M. (1967).A study of specific ability and attainment in Mathematics.British Journal of Educational Psychology, 37, 178 189

[13] Opasina, C. O. (2009). Development and validation of alternative to practical physics test using item response modules. Unpublished Doctoral Thesis, University of Ibadan, Nigeria

[14] Physics Education Technology Simulation (2006): Mass and springs a simulation retrieved from http://phetedu/en/ simulation/massuniversityof Colorado. USA.

[15] Piaget, J. (1993). "Piaget theory". In P. Mussen (Ed.) Handbook of Child Psychology, (4 ${ }^{\text {th }}$ ed.), Volume 1, New York: Wiley.

[16] Şengel, E., Özden, M. Y., Geban, O. (2002). The influence of the simulated experiments supported with computer high school students comprehending the displacement and velocity concepts. National Science and Mathematics Education Symposium Proceedings Book II, 1424 -1429. Ankara: METU.

[17] Tamir, P. (1977). How are the laboratories used? Journal of Research in Science Teaching, 14, 311-316.

[18] Walter Frendz Spring Pendulum 1998b. A simulation Retrieved on June 5, 2011 from http://www.walterfendt.de/lph14e/springpendulum. html.

[19] Walter Frendz(1998). Simple Pendulum: A simulation Retrieved on June 5, 2011 from http://www.walter-fendt.d/lph14e/pendulum.

[20] West African Examination Council (2010). Examiners' Report Physics 2, Lagos, Nigeria: Afi Prints.

[21] West African Examination Council (2011). Examiners' Report Physics 2, Lagos, Nigeria: Afi Prints.

[22] West African Examination Council (2012). Examiners' Report Physics 2 Lagos, Nigeria: Afi Prints.

[23] Yu Fen-Lee, Yu Ying Guo, and Hsiang-Ju. H. 2008. Explore Effective use of Computer Simulations for Physics Education. American Journal of Computers in Mathematics and Science Teaching. 27, 443-466.

[24] Zacharia, Z., and Anderson, O.R. 2003. The Effect of an Interactive Computer-Based Simulation Prior to Performing Laboratory Inquiry Based Experiment on Students' Conceptual Understanding of Physics. American Journal of Physics, 71, 18-29.

\section{Subject: \\ Topic: \\ Physics \\ Duration: \\ Experiment Using Simple Pendulum \\ Instructional Objectives}

At the end of the lesson, students should be able to

1. Set up a simple pendulum bob experiment using real equipment such as retort stand, meter rule, thread, stop watch and bob.

2. Take reading independently for $20,40,60,80$ and $100 \mathrm{~cm}$

3. Use the reading obtained to make a table for period, time, length $\frac{1}{\text { Time }}$ and $\frac{1}{\text { Lengt } h}$

4. Plot a graph $\mathrm{T}$ against $\frac{1}{L}$

Content

5. Find the slope of the graph.

1. Setting up a simple pendulum experiment using real equipment such as retort stand, meter rule, thread, stop watch and bob.

2. Taking of independent readings for given values

3. Constructing a table of values

4. Plotting of graph and findings the slope

5. Finding intercept between $\mathrm{X}$ and $\mathrm{Y}$ axis

Materials: Retort Stand, thread, bob, stop watch, meter rule

Presentation of Content

Materials: Retort stand, meter rule, thread, stop watch and bob.

\section{Presentation of Content}

The assistant:

STEP I: selects programme from the internet and set up the virtual experiment on simple pendulum by adjustment of necessary parameters

STEP II: asks the students to set up the simple pendulum experiment using the real life equipment such as retort stand, thread, stop watch, and meter rule.

STEP III: Take readings

STEP IV: asks the students to prepare a table of readings for $1, \mathrm{t}, \mathrm{T}, \frac{1}{T}, \mathrm{~T}^{2}$ and $\mathrm{e}$.

STEP V: asks the students to plot a graph of $\mathrm{T}_{2}$ against $\mathrm{L}$ and determine the slope of the graph on both axis (X and $\mathrm{Y})$.

STEP VI: asks the students to find $h$,if $h, t, 1$ are related by $h=1-\frac{g}{4 \pi^{2}} T^{2}$ 


\section{Students}

STEP I: Students carry out the experiments following the directives of the assistant on simple pendulum and take readings.

STEP II: Students plot graph, find the intercept on $\mathrm{y}$ and $\mathrm{x}$ axis and carryout simple calculation on simple pendulum

\section{APPENDIX II \\ LESSON NOTE FOR COMPUTER SIMULATED EXPERIMENT GROUP}

Subject: $\quad$ Physics

Topic: $\quad$ Experiment Using Simple Pendulum

Duration: $1 \mathrm{hr}: 20 \mathrm{mins}$

\section{Instructional Objectives}

At the end of the lesson, students should be able to

1. Set up a simple pendulum bob experiment using computer simulated experiment software developed by Walter Fendt (1998).

2. Take reading independently for $20,40,60,80$ and $100 \mathrm{~cm}$

3. Use the reading obtained to make a table for period, time, length $\frac{1}{\text { Time }}$ and $\frac{1}{\text { Lengt } h}$

4. Plot a graph T against $\frac{1}{L}$

5. Find the slope of the graph.

Content

1. Setting up a simple pendulum experiment

2. Taking of independent readings for given values

3. Constructing a table of values

4. Plotting of graph and findings the slope

5. Finding intercept between $\mathrm{X}$ and $\mathrm{Y}$ axis

Materials: Computer simulated experiment software developed by Walter Fendt (1998).

\section{Presentation of Content}

The assistant:

STEP I: selects programme from the internet and set up the virtual experiment on simple pendulum by adjustment of necessary parameters

STEP II: asks the students to set up the simple pendulum experiment in the virtual laboratory and use it to obtain readings for length $20,40,60,80$ and $100 \mathrm{~cm}$

STEP III: asks the students to prepare a table of readings for $1, \mathrm{t}, \mathrm{T}, \frac{1}{T}, \mathrm{~T}^{2}$ and $\mathrm{e}$.

STEP IV:asks the students to plot a graph of $\mathrm{T}_{2}$ against $\mathrm{L}$ and determine the slope of the graph on both axis $(\mathrm{X}$ and Y).

STEP V:asks the students to find $h, i f h, t, 1$ are related by $h=1-\frac{g}{4 \pi^{2}} T^{2}$

Students

STEP I: Students carry out the experiments following the directives of the assistant on simple pendulum and take readings.

STEP II: Students plot graph, find the intercept on $\mathrm{y}$ and $\mathrm{x}$ axis andcarryout simple calculation on simple pendulum

General way of setting up a simple pendulum experiment

You are provided with a pendulum bob, retort stand and clamp and meter rule, stop watch, in extensive thread and split cork.

1. Set up the experiment as demonstrated previously with the length of string at $20 \mathrm{~cm}$.

2. Set up a reference point at the equilibrium position of the bob. Measure and record the height " $h$ " of the bob from the cork $(20 \mathrm{~cm})$

3. Set the bob to oscillation through a small angle of about $\left(5^{\circ}\right)$ equilibrium position and record the time for 20 oscillation

4. Repeat the procedure for (1-3) for the length and find the average time " $T$ ". calculate the period of oscillation "T"

5. Repeat the procedure (1-4) for four more different length " $\mathrm{h} "=40,60,80$ and $100 \mathrm{~cm}$.

6. Plot a graph of $\mathrm{T}^{2}$ against "l" as abscissa. Determine the slope of the graph on both vertical (y) and horizontal (X) axis

7. If $\mathrm{h}, \mathrm{t}, \mathrm{l}$, are related by $\mathrm{h}=1-\frac{g}{4 \pi^{2}} T^{2}$, find " $\mathrm{g}$ ". 